\title{
AC 2012-5476: THE ROLE OF PRINT, WEB, AND SOCIAL MEDIA FOR RECRUITING STUDENTS
}

\section{Dr. Mary A. Sadowski, Purdue University, West Lafayette}

Mary A. Sadowski is currently the Interim Dean for the Purdue Extended Campus. She had been the associate dean for undergraduate programs and learning in the Purdue College of Technology since 2003, where she provided leadership for strategic initiatives in undergraduate education; serves as coordinator of accrediting activities and initiatives, scholarships, and enrollment management; and provides direction for activities related to student services. Her research interests include enhancing visualization skills, creative thinking, and learning styles. She is currently funded to begin gathering data to create a concept inventory for engineering graphics. As a professor at both Purdue University and Arizona State University, Sadowski's specialty is computer and technical graphics. She has taught a variety of courses, including CAD, web design, animation, and creative thinking. Sadowski received her B.S. from Bowling Green State University, her M.S. from The Ohio State University, and her Ph.D. from Purdue University.

\section{Prof. Judith A. Birchman, Purdue University, West Lafayette}

Judy Birchman is an Associate Professor in the Department of Computer Graphics Technology at Purdue University. As a member of the Computer Graphics Department, she has taught courses in engineering graphics fundamentals, drawing systems, CAD, print design, and multimedia. Birchman has served as the Technical Editor of the Engineering Design Graphics Journal, responsible for the review process. She also served as the Editor of the Engineering Design Graphics Journal. As a member of the Engineering Design Graphics Division, she has held elected positions on the executive board serving as Director of Publications, Division Vice-Cair and as Chair of the division. She is a member of the American Society for Engineering Education (ASEE) and the Engineering Design Graphics Division (EDGD).

\section{Mr. Brandon Xavier Karcher, Purdue University}

Brandon Xavier Karcher is a M.S. student, College of Technology, at Purdue University 


\title{
The Role of Print, Web, and Social Media in Recruiting Students
}

\begin{abstract}
Recruiting for higher education is a well-documented and practiced process; however, new social media venues of delivering information are changing the way some universities are reaching prospective students. Recruiting students for higher education has typically been accomplished by a variety of traditional methods, including print, Web, and campus visits. While these methods continue to be used, the existence of new social media including Twitter, Facebook, blogging, and message boards has pushed many universities towards recruiting in new ways. As we think about recruiting students into our programs, we are faced with many more choices than we have had in the past. We are also faced with students who are much more media savvy than previous students. There seems to be very little in the literature about the impact and usefulness of the newer social media outlet as recruiting tools. This study was designed to determine how effectively students perceive different recruiting methods (print, Web, and social media) as well as who helped them sort through all of the information to make their choices. First-semester freshmen in the College of Technology (CoT) at Purdue University were surveyed to determine how print, Web, and social media for recruiting are perceived by prospective students. They were asked what people influenced them during their college search and which forms of media influenced their decision-making process. This paper presents results of a Web survey conducted during fall 2010 and fall 2011.
\end{abstract}

\section{Introduction}

In fall 2010, an initial survey was conducted to evaluate the role that print, Web, and social media played in recruiting students to the College of Technology at Purdue. The survey was repeated during fall 2011. Recent changes in the economic climate have increased the focus on recruiting efforts at Purdue and other universities. In addition, a reduction in funding, and the increased online savvy of potential students and parents, has led universities to take a closer look at the costs and effectiveness of their recruiting efforts. The Web and social media offer a means 
to reach out to prospective students that is both economical and current. Like many others, the College of Technology at Purdue University has embarked on creating a presence in the realm of social media. Social media can be defined as “a group of internet-based applications that build on the ideological and technological foundations of Web 2.0, and that allow the creation and exchange of User Generated Content."1 Facebook and Twitter are two of the most prevalent social media outlets utilized by the College of Technology. This survey was used to gauge the awareness level of incoming students and determine the effectiveness of recruiting materials. The results of the 2010 and 2011 surveys were compared to see if the initial data held up, or whether a new trend was emerging, particularly in the realm of social media.

\section{Current Recruiting Methods}

\section{Face-to-face}

The College of Technology employed a variety of recruiting methods to recruit students into the fall 2010 and 2011 classes. The University has an expansive schedule of on-campus recruiting days for high school students who have not yet applied and other days for those who have already been admitted. The College of Technology participates in these face-to-face opportunities with a presentation about the college, tours of the college facilities, and meetings with faculty and academic advisors. In addition to the campus visits, College of Technology student services representatives visit a large number of Indiana high school Project Lead the Way classes. The representatives promote the college programs, network with the teachers, and discuss the need for high school mathematics and science. ${ }^{2}$

\section{Print}

The college has a variety of print publications; however, the major print recruiting piece is the College of Technology magazine. This annual publication is targeted towards high school students and their parents. It includes information about all of the technology programs as well as information about scholarships, student organizations, and vignettes of current students. Programs are grouped into four key areas rather than by individual majors: 1) computing, 2) engineering technology, 3) technology management, and 4) professional programs. In this manner, a student who is interested in computing will see all of the programs related to 
computing, a student who is interested in engineering technology will find all of those programs in the same place. ${ }^{2}$

\section{Web}

The College of Technology has had a Web presence for many years, which includes a link for prospective students. Students and parents who visit the Web site can explore the different majors in the college; they learn about the cost of attending Purdue, and how to apply to the University as well as how to apply for financial aid. They can also request information from the college, schedule a visit, read student blogs, or learn how to connect to the college via Facebook, Twitter, YouTube, or Flickr.

\section{Social Media}

While recruiting the fall 2010 class, the college did have a Facebook page and a Twitter presence; however, the college did very little with them. While recruiting the fall 2011 class, the college did emphasize Facebook, Twitter, YouTube, and Flickr on the college Web site. More effort was made to keep the social media sites current and interesting for prospective student and their parents. Announcements about the social media sites were included in e-mails and correspondence sent to prospective and admitted students through the postal service.

\section{Methodology}

The survey of 2011 first-year students was the same as the original study that was conducted with the 2010 first-year students. It should be noted that the 2010 survey was conducted during the spring semester, and the 2011 survey was conducted during the fall semester of the freshman year. The questions focused on determining what methods students used to find information about the College of Technology and the effectiveness of the various recruiting materials. Students also answered questions about their familiarity with the Web and social networks.

\section{The Survey}

The survey was developed through Qualtrics, an online survey development package. The survey used a combination of multiple-choice questions, a Likert Scale format, and open-ended 
questions. The survey took approximately ten minutes to complete and was e-mailed directly to the first-year students in the college.

The initial survey was developed by Computer Graphics Technology graduate student, Brandon Karcher, as part of his thesis. The survey was modeled on the Theory of Planned Behavior that was proposed and developed by Icek Ajzen ${ }^{3}$ in his paper, From Intentions to Actions: A Theory of Planned Behavior. According to the theory, decisions are guided by three considerations: behavioral, control, and normative beliefs. When these three beliefs combine, an intention is formed. The intention is then linked to a behavior, and depending on the perceived behavioral control an individual has, the behavior will be carried out. According to the theory, in order to make a decision, a person takes into consideration his/her perceived beliefs and attitudes, then develops an intention, and finally a behavior follows. To follow this model, questions are asked in a manner that allows for questions based on attitudes/beliefs, intentions to use various media, and, finally, questions regarding behaviors. ${ }^{4}$

To utilize the Theory of Planned Behavior, the survey posed questions in a manner that flowed chronologically, as well as in the same order of the theory. First, questions were asked about the students' experiences while enrolling in the College of Technology. Questions such as-Who or what influenced you the most in making the decision to attend the College of Technology (CoT)? —-were used to gather information regarding the students' beliefs and/or attitudes regarding different factors about parents, advisers, and mediums such as print or Web. Next, according to the theory, the intention or readiness to perform a behavior needed to be assessed. ${ }^{3}$ The survey covered multiple areas related to intention. Measuring students’ willingness to consider social media, and their intention to later use it as an information source, compares to the intention step in the Theory of Planned Behavior. Finally, the behavior section focused on how the students used, are currently using, and how they think the College of Technology could use media to recruit students. ${ }^{5}$

\section{Sample Population}

This study was conducted with fall 2010 and fall 2011 first-year students in the College of Technology. Only first-year students (freshmen) were included; students who had transferred into the program from another major or another university were not included in the study. 
The fall 2010 freshman class in the College of Technology consisted of 563 students, while the fall 2011 class consisted of 518 students. In both years, the males outnumbered the females by a considerable amount. (Table 1) In both 2010 and 2011, the class averaged 84.6 percent male. Participation in the survey was voluntary, and the subjects were not identifiable to the researchers. The survey was e-mailed directly to the students and results were recorded through Qualtrics. Of the students who received the survey, 57 responded in 2010 for a total of 10.0 percent. In 2011, 114 students responded for a total of 22.0 percent. In 2010, 19.0 percent of the respondents were female, compared to a 35.1 percent female response rate in 2011. During fall 2010 and 2011, the number of females in the first-year class ranged from 14.5 to 16.4 percent, which is very similar to the male-female ratio in the entire college population. ${ }^{6}$ The authors have speculated that the high number of female respondents might be a result of College of Technology recruiting efforts that target females and the Women in Technology student organization that has a large enrollment of first-year female students.

\begin{tabular}{|c|c|c|c|c|c|}
\hline $\mathbf{2 0 1 0}$ & Male & Percent & Female & Percent & Total \\
All CoT & 2,978 & 86.3 & 472 & 13.7 & 3,450 \\
First-Year & 468 & 83.6 & 92 & 16.4 & 563 \\
Respondents & 46 & 81.0 & 11 & 19.0 & 57 \\
\hline $\mathbf{2 0 1 1}$ & Male & Percent & Female & Percent & Total \\
All CoT & 2,862 & 85.5 & 486 & 14.5 & 3,348 \\
First-Year & 443 & 85.5 & 75 & 14.5 & 518 \\
Respondents & 74 & 64.9 & 26 & 35.1 & 114 \\
\hline
\end{tabular}

Table 1. College of Technology Population

\section{Results of the Study}

The purpose of this study was to gain insights into the question-What role does print, Web, and social media play in recruiting for higher education? The survey supplied information related to: 1) what attitudes students have regarding the different types of media used for recruiting; 2) which methods students used in searching for a potential university, and what were their experiences with those mediums; and 3) what other factors affected the recruitment process for potential students. 
The first set of questions was introduced as follows-Think back to when you were trying to select a college and answer the following questions. Table 2 shows how the prospective student first found out about the College of Technology. Where did they start their Purdue search? Did they know about the College of Technology prior to starting their search? Table 2 shows a change in the top three sources for initial knowledge of the College of Technology. Although Parents remained a top source of information, High School Advisor was replaced by Friends \& Relatives in the top three. As in the previous survey results, the majority of students started their search at the Purdue Web site. As indicated by the results, 46 percent of the prospective students started their search at the Purdue Web site. The previous results indicated that none of the students started at the CoT Web site, whereas, in the second group, 2 percent started at the CoT Web site. Similar to the previous results, the majority of prospective students seem to be unaware of the CoT Web site. CoT Facebook and CoT Twitter were non-factors.

\begin{tabular}{|l|c|c|}
\hline Media Type & Percent Fall 2010 & Percent Fall 2011 \\
Purdue Web site & $\mathbf{3 7 . 0}$ & $\mathbf{4 6 . 0}$ \\
High School Adviser & $\mathbf{1 5 . 0}$ & 7.0 \\
Parents & $\mathbf{1 5 . 0}$ & $\mathbf{1 2 . 0}$ \\
Other & 12.0 & 11.0 \\
Friends \& Relatives & 10.0 & $\mathbf{1 6 . 0}$ \\
CoT Promotional Material & 10.0 & 5.0 \\
CoT Event & 2.0 & 1.0 \\
CoT Facebook & 0.0 & 0.0 \\
CoT Twitter & 0.0 & 0.0 \\
CoT Web site & 0.0 & $\mathbf{2 . 0}$ \\
\hline
\end{tabular}

\section{Table 2. How did you first hear about the College of Technology?}

Table 3 shows the primary information sources prospective students used after they became aware of the College of Technology. The CoT Web site is indicated in the top three choices for 41.0 percent of respondents compared to 56.0 percent in the previous group. The College of Technology Web site still seems to be a valuable resource for information; however, CoT Promotional Material (print materials) dropped out of the top three choices and was reduced by almost 50.0 percent. Whereas, Friends \& Relatives almost doubled and moved into the top three; CoT Facebook showed a very slight increase (2.0 percent to 3.0 percent) from the previous 
survey. Knowing the influence of friends and relatives on prospective students, the college might want to make the CoT Facebook page more prominent overall.

\begin{tabular}{|l|c|c|}
\hline Media Type & Percent Fall 2010 & Percent Fall 2011 \\
Purdue Web site & $\mathbf{7 7 . 0}$ & $\mathbf{7 0 . 0}$ \\
CoT Web site & $\mathbf{5 6 . 0}$ & $\mathbf{4 1 . 0}$ \\
CoT Promotional Material & $\mathbf{3 1 . 0}$ & 16.0 \\
Parents & 27.0 & 21.0 \\
High School Advisor & 25.0 & 23.0 \\
CoT Event & 17.0 & 7.0 \\
Friends \& Relatives & 15.0 & $\mathbf{3 0 . 0}$ \\
Other & 13.0 & 13.0 \\
CoT Facebook & 2.0 & 3.0 \\
CoT Twitter & 0.0 & 0.0 \\
\hline
\end{tabular}

Table 3. When you were researching the College of Technology, what were your primary information sources? Choose top 3.

The last question in this set asks the prospective student to indicate what most influenced them to enroll in the College of Technology. Table 4 shows the most important factors that influenced their decision. In 2011, Friends \& Relatives moved into the top three and CoT Web site fell out of the top three. In both surveys, CoT Facebook and CoT Twitter remained at the bottom. It would appear that reaching out through social networks to prospective students' parents, friends and relatives, as well as high school advisors may influence recruiting. It appears that students use the Web and social media to gather information about colleges and programs; however, they do not rely as heavily on these sources when making their decision to attend. 


\begin{tabular}{|l|c|c|}
\hline Media Type & Percent Fall 2010 & Percent Fall 2011 \\
Parents & $\mathbf{6 0 . 0}$ & $\mathbf{5 2 . 0}$ \\
Purdue Web site & $\mathbf{4 4 . 0}$ & $\mathbf{4 6 . 0}$ \\
CoT Web site & $\mathbf{3 5 . 0}$ & 22.0 \\
Friends \& Relatives & 27.0 & $\mathbf{4 0 . 0}$ \\
High School Advisor & 23.0 & 12.0 \\
CoT Promotional Material & 23.0 & 11.0 \\
Other & 23.0 & 25.0 \\
CoT Event & 13.0 & 6.0 \\
CoT Facebook & 0.0 & 1.0 \\
CoT Twitter & 0.0 & 0.0 \\
\hline
\end{tabular}

Table 4. Who or what influenced you the most in making the decision to attend the College of Technology? Choose top 3.

The second set of questions was introduced as follows-Indicate your Internet usage and habits when you were a high school student. This portion of the survey determined the typical Internet and social media usage of these students while in high school. Table 5 shows the amount of time these high school students spent daily at various online tasks. As with the previous survey, while in high school, most of the respondents spent one to two hours primarily on homework with social networks ranking second in both surveys.

\begin{tabular}{|l|c|c|c|c|c|c|c|c|c|c|}
\hline Respondents & $\begin{array}{c}\text { Fall } \\
\mathbf{2 0 1 0} \\
\mathbf{\%}\end{array}$ & $\begin{array}{c}\text { Fall } \\
\mathbf{2 0 1 1} \\
\mathbf{\%}\end{array}$ & $\begin{array}{c}\text { Fall } \\
\mathbf{2 0 1 0} \\
\mathbf{\%}\end{array}$ & $\begin{array}{c}\text { Fall } \\
\mathbf{2 0 1 1} \\
\mathbf{\%}\end{array}$ & $\begin{array}{c}\text { Fall } \\
\mathbf{2 0 1 0} \\
\mathbf{\%}\end{array}$ & $\begin{array}{c}\text { Fall } \\
\mathbf{2 0 1 1} \\
\mathbf{\%}\end{array}$ & $\begin{array}{c}\text { Fall } \\
\mathbf{2 0 1 0} \\
\mathbf{\%}\end{array}$ & $\begin{array}{c}\text { Fall } \\
\mathbf{2 0 1 1} \\
\mathbf{\%}\end{array}$ & $\begin{array}{c}\text { Fall } \\
\mathbf{2 0 1 0} \\
\mathbf{\%}\end{array}$ & $\begin{array}{c}\text { Fall } \\
\mathbf{2 0 1 1} \\
\mathbf{\%}\end{array}$ \\
\hline Answer & \multicolumn{2}{|c|}{ None } & \multicolumn{2}{|c|}{$\mathbf{1 - 2}$ hours } & \multicolumn{2}{c|}{$\mathbf{3 - 4}$ hours } & $\mathbf{5 - 6}$ hours & \multicolumn{2}{|c|}{$\mathbf{7 + \text { hours }}$} \\
\hline Homework & 7.5 & 5.5 & 32.0 & 25.0 & 31.0 & 38.0 & 19.0 & 64.0 & 50.0 & 20.0 \\
Social & 7.5 & 4.5 & 29.0 & 32.0 & 36.0 & 28.0 & 37.0 & 23.0 & 12.5 & 70.0 \\
Video games & 51.0 & 59.0 & 15.0 & 17.0 & 15.0 & 13.0 & 25.0 & 9.0 & 12.5 & 10.0 \\
Other & 34.0 & 31.0 & 24.0 & 26.0 & 18.0 & 21.0 & 19.0 & 4.0 & 25.0 & 0.0 \\
\hline
\end{tabular}

Table 5. How much time per day did you spend on the Internet?

Table 6 shows the number of times the prospective student accessed the College of Technology Web site when searching for information. As in the first survey, most of the respondents indicated that they accessed the Web site two to five times in the course of their search. An additional question asked-Did your parent(s) or guardians(s) assist you in your search for a college? — to which, 74.0 percent (77.0 percent previous) responded “yes.” When 
asked to indicate all of the methods they used to search, the replies indicated that it was predominantly the Internet, 90.0 percent (82.0 percent previous); followed by campus visits, 74.0 percent (72.0 percent previous); and printed materials, 42.0 percent (67.0 percent previous). The top three choices remained the same although printed materials ranked lower than on the previous survey.

\begin{tabular}{|l|c|c|}
\hline Answer & Response Fall 2010 & Response Fall 2011 \\
\hline None & $10.0 \%$ & $11.0 \%$ \\
\hline 2-5 times & $\mathbf{5 6 . 0 \%}$ & $\mathbf{5 3 . 0 \%}$ \\
6-10 times & $26.0 \%$ & $23.0 \%$ \\
\hline More than 10 times & $8.0 \%$ & $12.0 \%$ \\
\hline
\end{tabular}

\section{Table 6. How many times did you visit the College of Technology Web site as part of your college search?}

Table 7 shows what social media these responders were using at the time of their college search. Once again, Facebook was the overwhelming response with Twitter a distant second. The follow-up question asked if they used social media in their college search. The majority, 63.0 percent (58.0 percent previous), indicated that they did not use social media in their college search. Of the remaining respondents that did use social media in their search, 13.0 percent (18.0 percent previous) found it very useful, 43.0 percent (50.0 percent previous) found it moderately useful, and 45.0 percent (32.0 percent previous) found it somewhat useful. When asked if they found useful information through a social network, 84.0 percent responded that they used Facebook, with only 11.0 percent using Twitter.

\begin{tabular}{|l|c|c|}
\hline Answer & Response Fall 2010 & Response Fall 2011 \\
Facebook & $\mathbf{9 8 . 0 \%}$ & $\mathbf{9 7 . 0 \%}$ \\
MySpace & $2.0 \%$ & $0.0 \%$ \\
Twitter & $\mathbf{1 8 . 0 \%}$ & $\mathbf{2 7 . 0 \%}$ \\
LinkedIn & $14.0 \%$ & $10.0 \%$ \\
Other & $6.0 \%$ & $8.0 \%$ \\
\hline
\end{tabular}

Table 7. Which major social media do you currently use?

Respondents were also asked if they knew that the College of Technology had a Facebook and Twitter presence and, if so, how did they find it. In response, only 38.0 percent (48.0 percent 
previous) answered that they were aware of the College of Technology Facebook and Twitter accounts. When asked how they learned about Facebook and Twitter, the responses were varied as with the previous survey and included random searches, from a friend, and the College of Technology Web site.

The last set of questions was introduced as follows-The following questions will have you evaluate the recruiting material. First, the prospective students were asked to evaluate the media used by the College of Technology and how it compared to other colleges they were researching. Second, they were asked which mediums were most helpful in their search. Once again, the College of Technology materials were shown to be effective in all four areas: visual appeal, informative, persuasive, and availability. The majority ranked the materials as a three or a four on the Likert scale as shown in Table 8.

\begin{tabular}{|c|c|c|c|c|c|c|c|c|}
\hline Respondents & $\begin{array}{l}\text { Fall } \\
2010\end{array}$ & $\begin{array}{c}\text { Fall } \\
2011\end{array}$ & $\begin{array}{l}\text { Fall } \\
2010\end{array}$ & $\begin{array}{c}\text { Fall } \\
2011\end{array}$ & $\begin{array}{l}\text { Fall } \\
2010\end{array}$ & $\begin{array}{l}\text { Fall } \\
2011\end{array}$ & $\begin{array}{l}\text { Fall } \\
2010\end{array}$ & $\begin{array}{c}\text { Fall } \\
2011\end{array}$ \\
\hline Answer & \multicolumn{2}{|c|}{ Worse 1} & \multicolumn{2}{|c|}{2} & \multicolumn{2}{|c|}{3} & \multicolumn{2}{|c|}{4 Better } \\
\hline Visual Appeal & 0 & 0 & 7 & 24 & 27 & 47 & 16 & 28 \\
\hline Informative & 1 & 0 & 6 & 13 & 23 & 51 & 19 & 35 \\
\hline Persuasive & 0 & 1 & 8 & 28 & 29 & 45 & 12 & 25 \\
\hline Availability & 1 & 1 & 5 & 17 & 24 & 49 & 19 & 32 \\
\hline Total & 2 & 2 & 26 & 82 & 103 & 192 & 66 & 120 \\
\hline
\end{tabular}

\section{Table 8. How did the College of Technology compare with other colleges?}

Another question asked respondents to rank the usefulness of various media types used by the College of Technology. As shown in Table 9, the top three choices were the CoT Web site, with the CoT Promotional Material and CoT Event next and relatively closely weighted. By comparison, CoT Facebook and CoT Twitter were the two lowest percentages. The results were very close for both rounds; however, CoT Facebook and CoT Twitter were ranked as less beneficial than in the first round. 
Fall 2010

\begin{tabular}{|l|c|c|c|c|c|c|c|}
\hline Media Type & $\begin{array}{c}\text { Not } \\
\text { Beneficial }\end{array}$ & $\mathbf{1}$ & $\mathbf{2}$ & $\mathbf{3}$ & $\mathbf{4}$ & $\begin{array}{c}\text { Extremely } \\
\text { Beneficial }\end{array}$ & $\begin{array}{c}\text { Percent } \\
>\mathbf{4}\end{array}$ \\
CoT Event & 5 & 2 & 12 & 9 & 9 & 9 & $\mathbf{3 9}$ \\
CoT Facebook & 11 & 10 & 5 & 11 & 7 & 2 & 20 \\
CoT Promotional Material & 3 & 3 & 6 & 16 & 8 & 12 & $\mathbf{4 2}$ \\
CoT Twitter & 26 & 9 & 2 & 4 & 4 & 1 & 11 \\
CoT Web site & 1 & 2 & 2 & 13 & 15 & 16 & $\mathbf{6 3}$ \\
\hline
\end{tabular}

Fall 2011

\begin{tabular}{|l|c|c|c|c|c|c|c|}
\hline Media Type & $\begin{array}{c}\text { Not } \\
\text { Beneficial }\end{array}$ & $\mathbf{1}$ & $\mathbf{2}$ & $\mathbf{3}$ & $\mathbf{4}$ & $\begin{array}{c}\text { Extremely } \\
\text { Beneficial }\end{array}$ & $\begin{array}{c}\text { Percent } \\
>\mathbf{4}\end{array}$ \\
CoT Event & 14 & 6 & 17 & 27 & 19 & 12 & $\mathbf{3 3}$ \\
CoT Facebook & 24 & 10 & 25 & 24 & 5 & 5 & 11 \\
CoT Promotional Material & 10 & 6 & 17 & 22 & 30 & 11 & $\mathbf{4 3}$ \\
CoT Twitter & 34 & 14 & 20 & 17 & 4 & 3 & 8 \\
CoT Web site & 7 & 0 & 11 & 20 & 29 & 32 & $\mathbf{6 2}$ \\
\hline
\end{tabular}

Table 9. Of the following College of Technology information sources, which ones did you find the most beneficial?

The final question asked what medium they think the College of Technology should use in the future for recruiting purposes. Table 10 shows the results. The top three choices were CoT Event, CoT Facebook and CoT Promotional Material. CoT Promotional Material (printed) replaced the CoT Web site in the top three choices in the second round. CoT Twitter was at the bottom of the rankings as in the first round.

\begin{tabular}{|l|c|c|}
\hline Answer & Response Fall 2010 & Response Fall 2011 \\
\hline CoT Event & $\mathbf{2 4 . 0 \%}$ & $\mathbf{2 7 . 0 \%}$ \\
\hline CoT Facebook & $\mathbf{2 9 . 0 \%}$ & $\mathbf{2 4 . 0 \%}$ \\
\hline CoT Promotional & $16.0 \%$ & $\mathbf{2 3 . 0 \%}$ \\
Material (print) & $4.0 \%$ & $3.0 \%$ \\
\hline CoT Twitter & $\mathbf{2 4 . 0 \%}$ & $19.0 \%$ \\
CoT Web site & $4.0 \%$ & $5.0 \%$ \\
\hline Other &
\end{tabular}

Table 10. How do you think the College of Technology should connect with current high school students? 


\section{Conclusions}

The study was designed to look at several questions:

1. What attitudes do prospective students have regarding the different types of media used for recruiting?

2. Which methods and media did prospective students use in searching for a potential university?

3. What were their experiences with those mediums?

4. Who influenced them during the decision making process?

This paper presented the results of a survey given to fall 2011 first-year students in the College of Technology at Purdue University. These results were compared with the results of the same survey given to fall 2010 first-year students. The surveys were administered at different times of the year. Fall 2010 students were surveyed during the spring semester of their freshman year, and fall 2011 students were surveyed during the fall semester of their freshman year. This may account for the low number of respondents for the first survey (fall 2010, 10 percent; fall 2011, 35 percent).

In both years, the Purdue Web site was the first point of contact for most of the respondents. The College of Technology Web site gained popularity once the students became aware of the college and its program offerings. Prospective students used many of the different avenues to become informed about the college; however, parents, friends and relatives, and the Web continue to be strong influencers when students are making the decision to attend Purdue.

Although only an average of 2.5 percent of the respondents indicated that they used Facebook to gather information about Purdue University and the College of Technology, 25 percent indicated that the College of Technology should use Facebook to connect with current high school students. One challenge will be for the college to determine how to attract prospective students to the College of Technology Facebook page and how to populate the site with information that will inform and connect with high school students. 
This survey was administered to first-year students who were enrolled in the College of Technology at Purdue University. It did not capture information from students who were accepted and chose not to attend. Capturing data from that population could be helpful in determining how to increase the yield of students who are accepted and choose not to attend.

\section{Bibliography}

1) Kaplan A., Haenlein, M. (2010). Users of the world, unite! The challenges and opportunities of social media. Business Horizons, 53(1), 59-68. doi:10.1016/j.bushor.2009.09.003

2) Sadowski, M. A., Birchman, J. A., Karcher, B. X. (2012). A study to examine the role of print, web, and social media for recruiting students. Global Graphics: An educational perspective, $66^{\text {th }}$ Mid-Year Conference Proceedings of the Engineering Design Graphics Division of ASEE.

3) Ajzen, I. (1985). From intentions to actions: A theory of planned behavior. In J. Kuhl \& J. Beckman (Eds.), Action-control: From cognition to behavior (pp. 11-39). Heidelberg: Springer.

4) Fishbein, M., \& Ajzen, I. (2010). Predicting and changing behavior: The reasoned action approach. New York: Psychology Press.

5) Karcher, B. (2011). Recruiting for higher education: The roles that print, web, and social media play in the decision process for prospective students. (Unpublished master's thesis). Purdue University. West Lafayette, IN.

6) Purdue Data Digest. (2011). College of Technology, Enrollment by Gender. http://www.purdue.edu/datadigest/students/school/tech/stu_gender.pdf. 